\section{BY JEFF TOLLEFSON}

W hat's in a number? This month, the world's attention turns to a big one: 7 billion, the latest milestone in humanity's remarkable and worrying rise in population. According to a calculation based on surveys, censuses, probabilistic analyses, human sleuthing, expert opinion, heated academic debates and not a little guesswork, 31 October 2011 is the most likely day that the number of living humans will top that figure. The date is a rough marker. Assuming a 1\% margin for error, the milestone might have arrived earlier this year, or may not be reached until 2012.

"It's a relatively simple accounting framework: only birth, death and migration can change a population," says Thomas Buettner, assistant director of the Population Division of the United Nations Department of Economic and Social Affairs in New York City, where the calculation was carried out on a standard desktop PC. "But there are a lot of conflicting data as well."

Errors and patchy data contribute to the uncertainty, but demographers must also deal with institutional bias (schools the world over have an interest in boosting their enrolment numbers), as well as political motivations. China's one-child policy, for instance, is the source of endless confusion: estimates of the actual fertility rate vary from 1.3 to 1.8 children per female, Buettner says, with vast consequences for projections of its future population.

On one level, a figure of 7 billion is incredible for the sheer momentum it represents: a full doubling of the planet's population since 1967, with current growth adding 200,000 people each day, and a nation larger than the size of France each year. But although the 6-billion mark was reached about 13 years ago according to revised figures, it will take nearly 14 years to hit 8 billion (see 'Snapshots of growth'). The comparison shows that population growth is decelerating; it is likely to level off at about 10 billion before the end of the century.

Between now and then, the fastest growth will be in Africa, where fertility levels remain higher than anywhere else in the world. Population levels among industrialized countries, by contrast, will remain relatively constant. Although Asia will remain the most populous continent, decreasing fertility rates there will add to the overall 'greying' of the planet.

Because high fertility is linked with poverty, the big worry globally is the 3.4 billion people who survive on less than US $\$ 2$ per day, says Joel Cohen, who heads the Laboratory of Populations at the Rockefeller University in New York. The average number of children per woman in the least developed countries is 4.5, compared with 1.7 for developed countries, Cohen says, and this means that most of the additions to the global count are born where there is little access to energy and education, further fuelling the population steamroller. This reality underscores the importance of international development efforts: small increases in wealth and education can lower fertility and dramatically ease the burden of population growth decades down the road.

As seen through the matter-of-fact perspective of the statistician: "If you are successful now," says Buettner, "the benefits accumulate over time."

\title{
SNAPSHOTS OF GROWTH
}

By the time the next billion people are added to the world's population it will not only be a more crowded planet but a perceptibly different one in terms of geography, age and modes of living. Yet even a small divergence from projected fertility rates could spell very different outcomes.
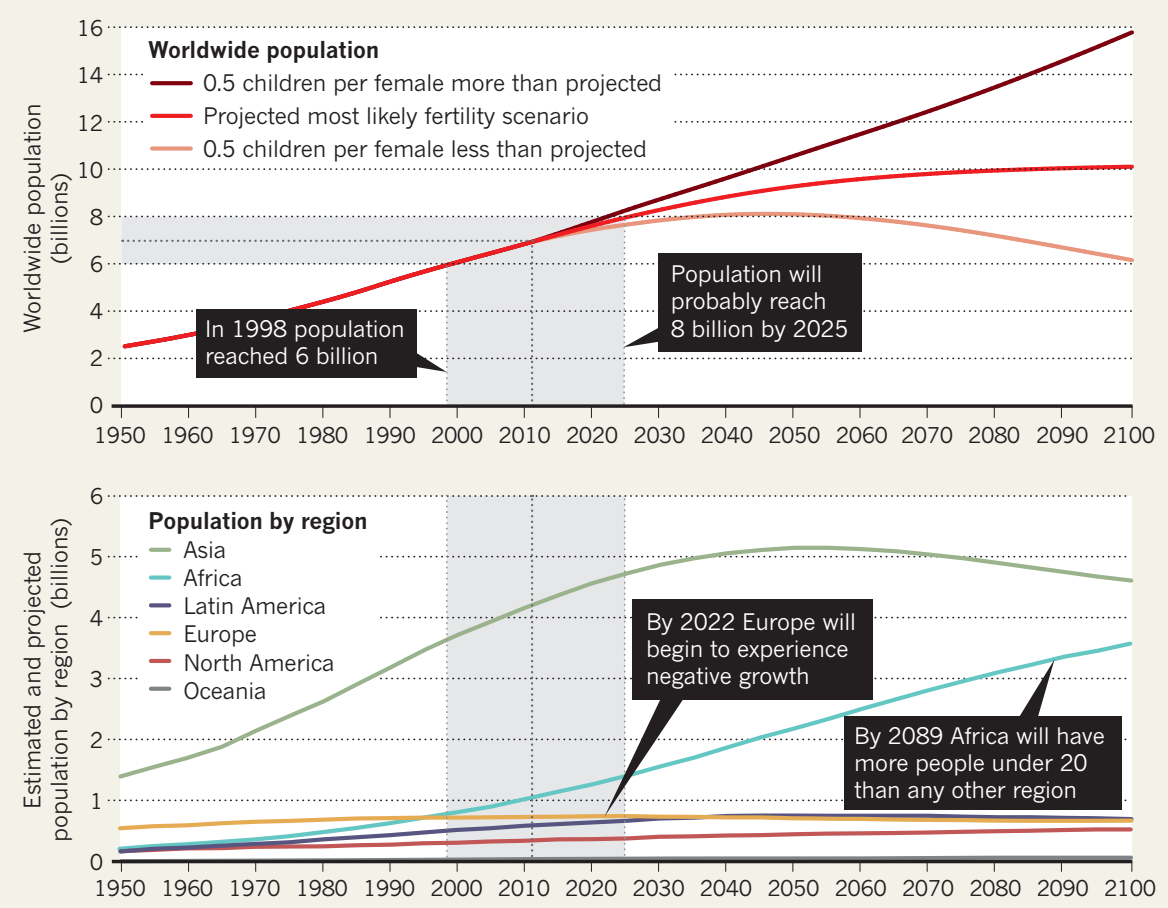

\section{URBANIZATION}

Between the last 'billion' milestone and the next, the number of city dwellers will grow by roughly 1.8 billion.

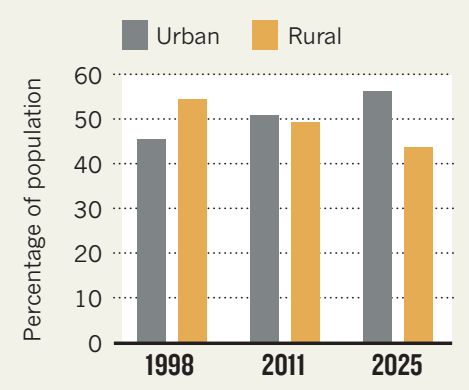

\section{AGEING}

Despite pockets of youth in developing countries where populations are booming, the world is generally getting older as people live longer.

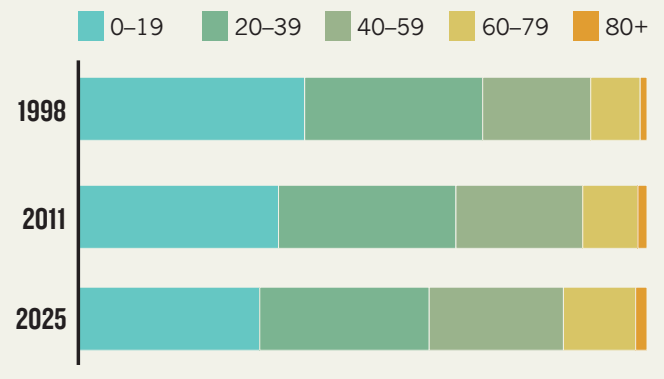

